Article

\title{
Depression and Spiritual Distress in Adult Palliative Patients: A Cross-Sectional Study
}

\author{
Teresa Velosa ${ }^{1, *}$ (D) , Sílvia Caldeira ${ }^{2}$ (1) and Manuel Luís Capelas ${ }^{2}$ \\ 1 Institute of Health Sciences, Universidade Católica Portuguesa, Palma de Cima, 1649-023 Lisbon, Portugal \\ 2 Institute of Health Sciences, Centre for Interdisciplinary Research in Health, Universidade Católica Portuguesa, \\ Palma de Cima, 1649-023 Lisbon, Portugal; scaldeira@ics.lisboa.ucp.pt (S.C.); \\ luis.capelas@ics.lisboa.ucp.pt (M.L.C.) \\ * Correspondence: teresavelosa@gmail.com; Tel.: +351-915-152-884
}

Received: 9 June 2017; Accepted: 16 August 2017; Published: 19 August 2017

\begin{abstract}
Palliative care patients have been associated with a high probability of having depression and spiritual distress. However, there is a gap in research about the clinical indicators that can promote an effective differential diagnosis of depression and spiritual distress. This study aimed to identify the prevalence and the clinical indicators of depression and spiritual distress in palliative patients in primary care. An observational and cross-sectional study was conducted in 2016 in a Portuguese primary care unit. From a General Practitioners patients' file of 1457 adult patients, a sample of 30 palliative patients was recruited throughout two steps: (1) selection of patients with chronic disease criteria; (2) selection of patients with Prognostic Indicator Guidance criteria. Exclusion criteria included cognitive impairment and psychotic disorders. Participants completed the self-assessment Hospital Anxiety and Depression Scale (HADS) and Functional Assessment of Chronic Illness Therapy-Spiritual Well-Being Scale (FACIT-Sp12) scales, which were sealed in opaque envelopes. Clinical data collection used semi-structured interviews for the diagnosis of depression and spiritual distress. The prevalence of depression was $23 \%(n=7)$, while the prevalence of spiritual distress was $23 \%(n=7)$. Four patients $(13 \%)$ fulfilled both the depression and the spiritual distress criteria. Depression and spiritual distress seem to be both linked to the spiritual dimensions of the human being, but seem to differ in the dimensions of suffering and pharmacologic treatment.
\end{abstract}

Keywords: depression; spiritual distress; palliative care; spirituality

\section{Introduction}

\subsection{Palliative Care}

Palliative care is an approach that improves the quality of life of patients and their families who are facing problems associated with life-threatening illnesses (WHO 2015). It is intended to prevent and relieve suffering through the early identification, correct assessment and treatment of pain and other problems, whether they are physical, psychosocial, or spiritual. Palliative care is concerned not only with managing physical pain, but, as perceived by a palliative care community physician, with "the management of psycho-social struggle, the psycho-social pain and suffering that goes with dying" (Mistry et al. 2015, p. 3). A phenomenological study that enrolled a range of community palliative care providers emphasized the importance of this holistic palliative care approach. This study valued the following as much as the traditionally symptom-oriented concerns: the addressing of the patients' non-physical needs and wishes, the importance of having a healthcare team that functioned as a unit, the delivery of care that was patient-directed (namely seeking to understand the patients' and families' journeys), the importance of ensuring the patient is comfortable, and communication and relationship development in addition to the emotional preparation of the patient for a peaceful death (Mistry et al. 2015). 


\subsection{Depression}

Depression is one of the most prevalent forms of mental health problems, affecting about $21 \%$ of palliative cancer patients (Wilson et al. 2007), 20\%-29\% of patients with heart failure (Yohannes et al. 2010), $23 \%$ of patients with chronic obstructive pulmonary disease (Kunik et al. 2005), and $20 \%-44 \%$ of end-stage renal disease patients treated with hemodialysis (Cukor et al. 2014). Depression can have devastating effects on individuals and their families.

Sadness is a part of human existence and usually does not require treatment. Therefore, these periods should not be diagnosed as a depressive episode if they do not meet the severity and duration criteria or if they do not include clinically significant distress or impairment (APA 2013). Depression is a state of suffering characterized by sadness and emptiness, accompanied by somatic and cognitive changes that significantly affect the individual's capacity to function (APA 2013). Depressed mood or anhedonia (diminished interest or pleasure in activities), which has continued for at least a two-week period, is necessary to diagnose major depression. During this time, the patient must also exhibit at least five or more of the following symptoms: significant weight loss or gain; insomnia or hypersomnia; psychomotor agitation or retardation; fatigue or loss of energy; feelings of worthlessness or inappropriate/excessive guilt; diminished ability to think or concentrate; indecisiveness; and recurrent thoughts of death or suicide (APA 2013).

Patients with depression express themselves as feeling sad, low, empty, hopeless, and gloomy, with a loss of interest and enjoyment and increased fatigability. They can be unable to cry or frequently weep without significant precipitants and be irritable or cranky. The physician often observes changes in the patients' posture, dress, speech, and facial expression. Family members or co-workers notice patients' social withdrawal or decreased activity. Sometimes, pronounced somatic symptoms or psychotic symptoms accompany depression. The patient "commonly expresses feelings such as why me? What is the point? Why can't I find a point in living?"(Swinton 2001, p. 96).

Risk factors for major depressive disorder include families with a history of depression or alcoholism; race (less common in blacks); recent negative life events; insecure, worried, introverted, stress sensitive, obsessive, unassertive and dependent personality traits; early loss; disruptive, hostile or negative environment during childhood; lack of intimate relationships; and being postpartum (Loosen et al. 2000).

There is a consensus that depression results from multiple etiologic influences, including genetic, biochemical, psychodynamic, and socioenvironmental factors, which interact in complex ways (Loosen et al. 2000). "Stressful and significant life events, particularly the death or loss of a loved one, can precede the onset of depression, although fewer than $20 \%$ of individuals experiencing losses become clinically depressed" (Loosen et al. 2000, p. 290). Three behavioral models emerged in the mid-1900s to explain depression: "an inadequate positive reinforcement leading to a self-perpetuating cycle consisting of dysphoria, a reduction in behaviors that would normally obtain the reinforcement with lowered self-esteem, increased hopelessness, and increased isolation; a result of situations in which a person has lost control over negative life events; and as a distorted experience in the negative direction" (Loosen et al. 2000, p. 292). Biological theories associate depression with neurotransmitters and neuroendocrine factors. More recently, structural neuroimaging studies of depression have revealed widespread cortical-limbic deficits in grey matter and in white matter (Sankar et al. 2016).

Depression often has a negative impact on the patient's quality of life, but it can also be a process that opens the patient up to reflection. This also creates a possibility for therapeutically reframing personal needs and mental health (Swinton 2001).

\subsection{Anxiety}

Anxiety is one of the most prevalent mental disorders, affecting about $15 \%$ of the general population at any one time (Shelton 2000). When diagnosed by structured clinical interviews, the prevalence in palliative care patients varies between $14 \%$ in cancer (Wilson et al. 2007), $18 \%$ in chronic heart failure (Haworth et al. 2005), 19\% in chronic obstructive pulmonary disease (Kunik et al. 2005), 
and $46 \%$ in end-stage renal disease patients treated with hemodialysis (Cukor et al. 2008). Mixed anxiety and depression affects about $50 \%-66 \%$ of patients in palliative care or in primary care (Wilson et al. 2007; Hirschfeld 2001).

"Fear is the emotional response to real or perceived imminent threat, whereas anxiety is the anticipation of future threat" (APA 2013, p. 189). Anxiety disorders occur either when the response to the threat is excessive or when anxiety symptoms occur persistently without an obvious external threat (Shelton 2000). Anxiety is characterized by physical symptoms, such as tension, tachycardia, tachypnea, tremor, heart palpitations, sleep disturbances, shortness of breath, sweating, numbness, or tingling sensations. It is also accompanied by apprehension, fear, obsessions, feelings of unreality or of being detached from oneself, fear of losing control or "going crazy", fear of dying, and other similar symptoms (APA 2013). Anxiety disorders must be distinguished from anxiety due to another medical condition and from substance/medication-induced anxiety (APA 2013; Shelton 2000).

\subsection{Alcohol Use Disorder}

Harmful use of alcohol is one of the leading worldwide causes of morbidity, disability, and mortality. Each year, alcohol consumption is responsible for $5.9 \%$ of worldwide deaths and $5.1 \%$ of global burden of disease and injury, as measured in disability-adjusted life years (WHO 2014).

Alcoholism or alcohol use disorder is a maladaptive pattern of alcohol use leading to clinically significant impairment or distress. This is manifested by at least two or more of the following summarized criteria occurring within a 12-month period: consuming more alcohol than planned, unsuccessful efforts to control alcohol use, spending an excessive amount of time in activities necessary to use or recover from alcohol use, craving, failing major role obligations or social withdrawal attributable to alcohol use, continuous alcohol use despite recurrent social or interpersonal problems or despite health problems, tolerance, repeated use of alcohol in dangerous situations, and withdrawal symptoms (APA 2013).

In 2006, White, Becker and Laudet conducted 50 in-depth qualitative life history interviews with residents in addiction recovery. Surviving active addiction and achieving recovery was found to be associated with a higher meaning and purpose in the lives of the study participants (White et al. 2006). The authors described four primary sources of life meaning and purpose shared across these recovery frameworks: survival, self-reclamation, service to others, and connection to community (White et al. 2006). Furthermore, long-term trends seems to increase in the Purpose in Life scale with remission of alcohol dependence, while negative correlations were found for baseline Purpose in Life scores with drinking and depression (Krentzman et al. 2015).

\subsection{Spirit and Spirituality}

In its etymology, the spirit is the "élan vital" or "vital force" in French, while in Hebrew it is "ruách," which means "wind" or "breath." For Stein, the Spirit manifests itself entirely when it gives itself up and leaves without losing itself (Stein 1994). In 1988, Beck, Rawlins and Williams (Williams et al. 1993) conceptualized the Spirit as a movement that permeates the five dimensions of the human person (physical, intellectual, emotional, social, and spiritual) as the core aspect of the person, which manifests in people's thoughts, behavior, and language (Swinton 2001). Spirit can be observed, understood, and nurtured (Swinton 2001).

In the middle of the 20th century, Viktor Frankl highlighted the concept of spirituality as a core aspect of humankind (Frankl 1985). Since then, the concept of spirituality has gained widespread attention in several disciplines, including psychiatry. Despite the difficulty of formulating precise definitions, spirituality and religion relate to the core beliefs, values, and experiences of human beings (Moreira-Almeida et al. 2016). WHO has recognized spirituality as having a great impact on the patient's overall quality of life (Moussavi et al. 2007). In a consensus conference aiming to define spirituality in palliative care, the concept was defined as: "the aspect of humanity that refers to the way individuals seek and express meaning and purpose and the way they experience their connectedness to the moment, 
to self, to others, to nature, and to the significant or sacred" (Puchalski et al. 2009, p. 887). Overall, spiritual care should be based on a shared understanding of spirituality, which is a multidisciplinary approach. This care should include both assessment and treatment of spiritual distress. This report includes that spiritual distress "should be treated with the same intent and urgency as treatment for pain or any other medical or social problem" (Puchalski et al. 2009, p. 891).

The correct identification of a palliative patient's spiritual needs can help in overcoming the deterioration of their physical and social condition (Risk 2013). Focusing on their inner and spiritual being can be an important coping mechanism (Risk 2013).

\subsection{Spiritual Distress}

It is estimated that about half of cancer patients and others with chronic diseases experience some spiritual struggle (Delgado-Guay et al. 2011; Hui et al. 2011), although there is limited research examining the prevalence of spiritual distress among patients with cancer and other chronic diseases. This fact has recently been recognized as a priority in palliative care practice and research (Selman et al. 2014). Spiritual distress has been observed in palliative patients (Gielen et al. 2017) in addition to patients with cancer (Caldeira et al. 2014), heart failure (Naghi et al. 2012; Strada et al. 2013), respiratory insufficiency (Strada et al. 2013), kidney failure (De Cássia Lopes Chaves et al. 2010), and mental illness (Yang et al. 2012). Cancer patients may have spiritual distress at the diagnosis phase, at recurrence, and later in the terminal phase (Murray et al. 2005). Patients with organ failure may have spiritual distress along the illness journey, reflecting the gradual decline (Murray et al. 2005).

Viktor Frankl's personal experiences and study during the Second World War, when he survived concentration camps, led him to consider Man as a spiritual being. Thus, we structurally seek meaning (Frankl 1968). Each person has a unique meaning in life, which is critical to the sense of fulfilment (Frankl 1992). "The concern or even the despair of the person about whether their life is worth being experienced is an existential anguish, but by no means a mental illness. [...] The search for meaning certainly can cause inner tension instead of inner balance. However, precisely this tension is an indispensable prerequisite for mental health" (Frankl 1985, pp. 125-26).

When analyzing the defining characteristics for the nursing diagnosis of spiritual distress, a lack of meaning in life was found to be a fundamental spiritual need and a core aspect of spiritual distress among other defining characteristics (Caldeira et al. 2013). In addition, when conducting the clinical validation study, a lack of meaning in life had the highest specificity value among all defining characteristics in cancer patients in spiritual distress. Furthermore, expressing suffering had the highest value of sensitivity. Spiritual Distress was defined as a state of suffering that was related to lack of meaning in life (Caldeira et al. 2015).

\subsection{Depression and Spiritual Distress}

An ethnographic study conducted in a Spanish monastery whose community consisted of 10 contemplative nuns concluded that symptoms perceived as a depressive episode reflected a spiritual experience (Durà-Vilà et al. 2010).

They observed "clearly three key elements of the analysis: (1) a number of seemingly pathological symptoms, which bear great similarity with or were identical to those ascribed to depression (e.g., tearfulness, low mood, lack of volition, loss of appetite, etc.); (2) behavioural patterns and emotions which did not correspond to depression (maintenance of activities, sociability, preservation of hope, optimism despite the frustration, etc.); and (3) an attribution of meaning (religious meaning in the idiom of the Dark Night of the Soul), which facilitated (2) in spite of (1)". (Durà-Vilà et al. 2010, p. 557)

Swinton conducted a hermeneutic phenomenological study using unstructured interviews of people who had experienced depression for at least two years. One of the main themes arising from the research was the importance of having a meaning or purpose in life. Therefore, the author 
suggested that one of the defining features of depression could be a loss of meaning or purpose in life (Swinton 2001), which is also a core aspect of spiritual distress (Caldeira et al. 2013; 2015).

Quantitative studies have demonstrated that there is an inverse relationship between spirituality and depression, even in different cultures (Bekelman et al. 2007; Saisunantararom et al. 2015). Bornet et al. (Bornet et al. 2015) have tested two instruments for measuring depressive symptoms and spiritual distress, namely the Geriatric Depression Scale (GDS) and the Spiritual Distress Assessment Tool (SDAT). They observed that "96.4\% (27/28) of elderly patients with significant depressive symptoms (GDS-15 $\geq 6$ ) also suffered from spiritual distress. Conversely, elderly patients with high SDAT scores had a wide range of scores on the GDS-15" (Bornet et al. 2015, p. 109). They suggested that elderly patients with significant depressive symptoms might be more vulnerable to concomitant spiritual distress. Therefore, precise therapeutic interventions might be needed as spiritual distress and depression are different dimensions (Bornet et al. 2015).

There are overlapping symptoms between depression and spiritual distress, such as sadness, anger, despair, questioning (meaning of life, meaning of suffering, and system of beliefs), insomnia, pain, and other physical symptoms. In a study with elderly cancer patients, a significant association was observed between spiritual distress and taking antidepressant medication (Caldeira et al. 2014). Exploring the most sensitive clinical indicators of depression and spiritual distress seems necessary for creating differential diagnoses and the implementation of effective interventions, both pharmacological and non-pharmacological, within a multidisciplinary healthcare team.

The present study extends previous qualitative and quantitative research that suggests that meaning in life is a core aspect of the human person, with a lack of this dimension possibly being related to depression, addiction, and spiritual distress. Notwithstanding the similarities between depression and spiritual distress, previous research suggests they represent distinct health situations.

This study focused on applying previously defined criteria of spiritual distress and depression to the clinical setting, which is supported by depression, anxiety and spiritual well-being scales. Thus, the present study was designed to evaluate the prevalence of depression and spiritual distress in palliative patients in a primary care health unit in Portugal. Furthermore, we aimed to characterize the clinical, depressive, and spiritual features of the identified patients to test the similarities and the differences between palliative patients diagnosed with depression and spiritual distress within the sample.

\section{Methods}

\subsection{Design}

A quantitative, observational, cross-sectional, descriptive, and partially analytical study was conducted in 2016 in a Portuguese primary care unit.

We hypothesized that there would be palliative patients with one clinical diagnosis or neither. The main objectives of this study were to test the differences between depression and spiritual distress in regard to: spiritual distress main defining characteristics; the use of psychotropic medication; Functional Assessment of Chronic Illness Therapy Spiritual Well Being Scale (FACIT-Sp12) scoring; Hospital Anxiety and Depression Scale (HADS) scoring; clinical diagnosis codified by the International Classification for Primary Care-2 (ICPC-2).

Thus, the null hypothesis was as follows: there is no relationship between depression and the expression of suffering and lack of meaning in life (1A); there is no negative relationship between depression and FACIT-Sp scores (2A); there is no relationship between the use of antidepressants and FACIT-Sp scores (3A); there is no relationship between the use of sedative/anxiolytic medication and FACIT-Sp scores (4A); there is no relationship between depression and clinical diagnosis (5A); there is no relationship between spiritual distress and psychotropic medication (6A), HADS scoring (6B) and clinical diagnosis (6C); there is no relationship between FACIT-Sp scores and HADS scores considering HADS subscales (7A). 


\subsection{Participants}

Patients with chronic diseases and Prognostic Indicator Guidance (PIG) criteria were recruited from files of General Practitioner (GP) patients. Selection was accomplished in two steps: a selection based on the chronic disease criteria followed by a selection based on the prognostic indicator guidance criteria (PIG).

The chronic disease inclusion criteria included cardiovascular disease with evidence of organ damage, heart failure stages III/IV (NYHA), malignant disease, Chronic Obstructive Pulmonary Disease (COPD), cystic fibrosis, genetic/auto-immune/viral/alcoholic hepatic disease, kidney failure stages IV/V, multiple sclerosis, Parkinson's disease, Huntington's disease, upper motor neuron disease, AIDS, and other serious diseases with limited prognosis. Exclusion criteria included cognitive impairment defined by previous diagnosis of dementia or through the application of the mini mental state examination (MMSE) evaluation in addition to psychotic or personality disorders.

The National Gold Standards Framework developed PIG criteria, which aimed for early recognition of patients expected to die in the next 12 months by GPs. PIG criteria suggests three steps for the identification of patients nearing the end of life: (1) a negative answer to the question "Would you be surprised if this patient were to die in the next few months, weeks or days?"; (2) positive general indicators of decline; and (3) positive specific indicators of decline (Keri Thomas and GSF team 2011).

A total of 30 patients were enrolled in the study (Figure 1).

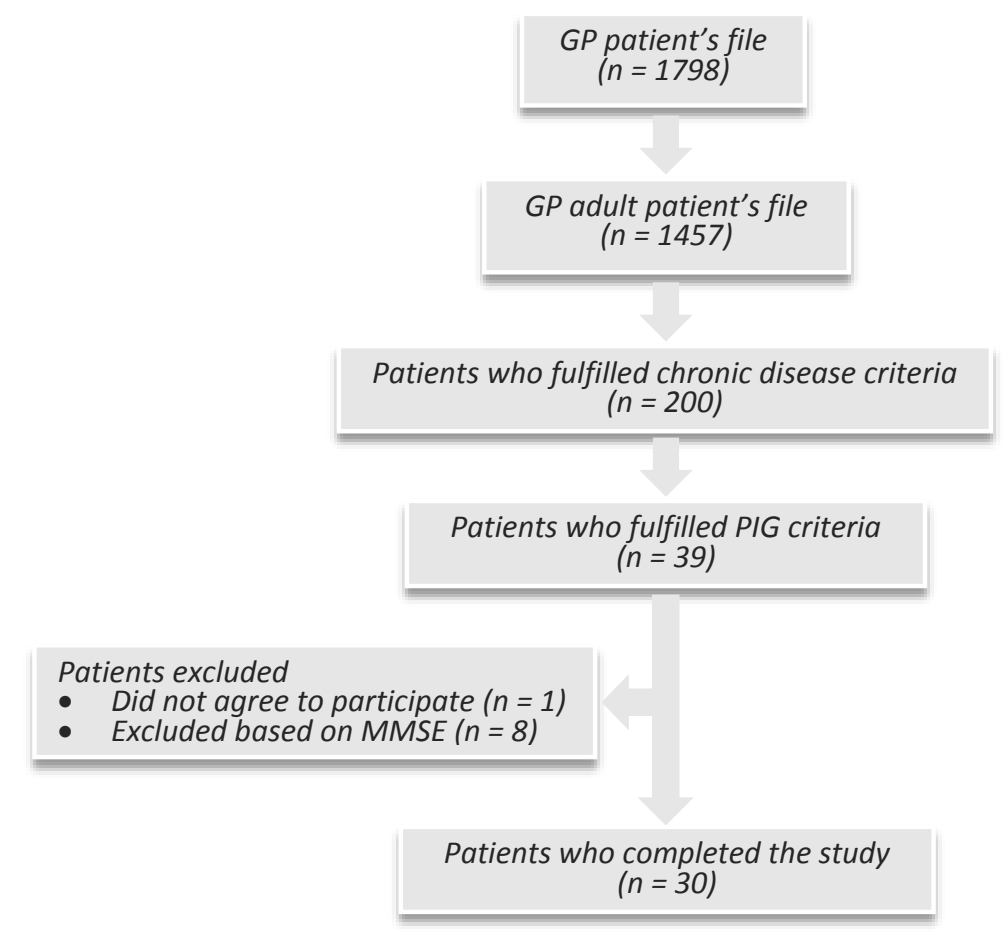

Figure 1. Study enrollment flowchart.

\subsection{Procedures}

\subsubsection{Ethical Issues}

The study was approved by the Ethical Committee of the Institute of Health Sciences of Universidade Católica Portuguesa. Data collection was performed with the support of personal assistants, according to a protocol outlined and approved by the primary health care unit. Informed consent was provided in the oral and written forms. Participants were informed of the possibility of quitting the study at any time or refusing to answer any questions if they felt uncomfortable. 
Consultations were rescheduled whenever necessary to a convenient time and day for the patient, which also occurred in the researcher's free time.

\subsubsection{Pilot Study}

A feasibility study with 10 participants was undertaken to identify practical problems in following the research procedure. The feasibility study was also a training opportunity for the identification of the defining characteristics of spiritual distress and the application of the spiritual distress diagnosis by the researcher. The feasibility study enrolled patients with a chronic disease with or without palliative criteria. A GP from the same health care unit provided a list with some of their adult patients who fit the desired criteria. These patients followed the study procedures.

\subsubsection{Data Collection Phases}

The first data collection phase occurred in a separate room where participants had been allowed to complete the HADS and FACIT-Sp questionnaires by themselves. Due to the low literacy levels of participants perceived in the feasibility study, personal assistants stayed with the participants and read the items if necessary. After completing HADS and FACIT-Sp questionnaires, these were delivered in opaque and closed envelopes to the personal assistant, who kept them shelved in a proper place until the end of the study. The second data collection phase occurred during the consultation period, during which the researcher gathered sociodemographic and clinical data, including the presence or absence of spiritual distress and depression.

\subsection{Measures}

\subsubsection{Instruments to Assess Depressive Symptoms and Spiritual Distress}

- The present study used the most recent MMSE normative values for the Portuguese population for the assessment of the exclusion criteria regarding the cognitive status (Morgado et al. 2009).

- HADS scale has been widely used in palliative care and primary care. It has two subscales, depression (HADS-D) and anxiety (HADS-A), which each have seven items. Each item is scored from 0 to 3. Each subscale total score ranges from 0 to 21. The cutoff threshold of 11 is used for depression and anxiety (Pais-Ribeiro et al. 2007). The HADS Portuguese edition has been used as a two-dimensional scale, with Cronbach's alpha value being 0.81 for depression and 0.76 for anxiety (Pais-Ribeiro et al. 2007). The HADS scale measures exclusively non-somatic symptoms, which is thus useful in patients with advanced medical conditions. The HADS questionnaire was fully completed by all study participants.

- FACIT-Sp12 has been designed to measure spiritual well-being in patients with cancer and other chronic illnesses. FACIT-Sp is comprised of 12 items and each item is scored from 0 to 4 . The total score ranges from 0 to 48 . FACIT-Sp comprises two subscales of meaning/peace and faith, which represent the two dimensions of spirituality. The horizontal dimension measures a sense of meaning, peace and harmony in life, while the vertical dimension measures feelings of strength and comfort in one's faith during physical illness (Peterman et al. 2002). The FACIT-Sp scale was chosen as it emphasizes the search for meaning in life, which is a central aspect of spiritual distress and a possible aspect of depression. The FACIT-Sp12 Portuguese edition has been validated in palliative cancer patients with good internal consistency (Cronbach's alpha $=0.92)$, and test-retest reliability ( $r$ of 0.99 ) (Pereira and Santos 2011). In four participants, up to two items were left unanswered. Therefore, those scores were prorated as indicated by the FACIT Administration and Scoring Guidelines.

\subsubsection{Clinical Assessment}

- The diagnosis of depression was based on a semi-structured clinical interview, which was further supported by HADS and the patient's medical history. The researcher filled in a short form, which 
included DSM-5 criteria and HADS results. Additionally, the form included sociodemographic variables, the medical history, the current psychiatric diagnosis including alcoholism and the current psychotropic medication. The clinical interview followed a DSM-5 criteria sheet.

- A diagnosis of spiritual distress was obtained through a three-part criteria: (1) the researcher's classification based on the identification of previously defined criteria for spiritual distress (Table 1)-patients who expressed suffering and expressed a lack of meaning in life were considered as clinically having spiritual distress; the defining characteristics for spiritual distress in these patients are presented in Table 1; (2) the patient's confirmation of spiritual distress throughout, via a positive answer to the question "In your opinion do you think you are suffering due to lack of meaning in life? Do you think you have spiritual distress?"; (3) a FACIT-Sp score below 36, which is the cutoff point defined for spiritual well-being (McClain et al. 2003). Patients who fulfilled all three of the abovementioned criteria were diagnosed as having spiritual distress.

Table 1. Defining characteristics of spiritual distress in palliative patients.

\begin{tabular}{|c|c|c|c|c|c|c|c|}
\hline Age & Sex & Expresses & & & & & \\
\hline $54 *$ & $\mathrm{~F}$ & $\begin{array}{l}\text { Anger toward } \\
\text { God/divinity }\end{array}$ & $\begin{array}{l}\text { Lack of meaning } \\
\text { in life }\end{array}$ & Lack of serenity & Suffering & & \\
\hline $57 *$ & M & Alienation & Anger & $\begin{array}{l}\text { Inability to } \\
\text { experience } \\
\text { transcendence }\end{array}$ & Lack of love & $\begin{array}{l}\text { Lack of meaning } \\
\text { in life }\end{array}$ & Suffering \\
\hline $68^{*}$ & M & $\begin{array}{l}\text { Concerns about } \\
\text { beliefs and values } \\
\text { system }\end{array}$ & $\begin{array}{l}\text { Lack of } \\
\text { confidence }\end{array}$ & $\begin{array}{l}\text { Lack of meaning } \\
\text { in life }\end{array}$ & Grief & $\begin{array}{l}\text { Regret and need } \\
\text { for forgiveness }\end{array}$ & Suffering \\
\hline $74 \ddagger$ & $\mathrm{F}$ & Emptiness & Grief & Hopelessness & $\begin{array}{l}\text { Lack of meaning } \\
\text { in life }\end{array}$ & $\begin{array}{l}\text { Sleep } \\
\text { disturbance }\end{array}$ & Suffering \\
\hline $\begin{array}{l}75 \\
* *\end{array}$ & M & Alienation & $\begin{array}{l}\text { Anger toward } \\
\text { God/divinity }\end{array}$ & Grief & $\begin{array}{l}\text { Lack of meaning } \\
\text { in life }\end{array}$ & $\begin{array}{l}\text { Regret and need } \\
\text { for forgiveness }\end{array}$ & Suffering \\
\hline $77 \ddagger$ & M & Lack of hope & $\begin{array}{l}\text { Lack of meaning } \\
\text { in life }\end{array}$ & $\begin{array}{l}\text { Regret and need } \\
\text { for forgiveness }\end{array}$ & Suffering & & \\
\hline $80 ł$ & M & Despair & Hopelessness & $\begin{array}{l}\text { Lack of meaning } \\
\text { in life }\end{array}$ & Suffering & & \\
\hline
\end{tabular}

\subsection{Data Analysis}

Comparisons were conducted using independent $t$-tests to test differences across continuous dependent variables; the Shapiro-Wilk test was used to check for normality of data; the chi-squared test to compare differences between sets of categorical data; the Mann-Whitney $U$ test to compare differences between two independent groups when the dependent variable was not normally distributed; and Spearman's rank-order correlation to measure the strength and direction of association between two ranked variables, when one of them was not normally distributed. A significance level of $\alpha=5 \%$ was used. Data were analyzed using SPSS Statistics 24 .

\section{Results}

\subsection{Phase 1-Chronic Disease Patients' Characteristics}

A sample of 200 patients having 293 chronic disease criteria was obtained. Accordingly, 135 patients had one single chronic disease criteria and 65 patients had two to four chronic disease criteria. Chronic diseases were classified as cardiovascular disease $(n=178)$, malignant disease $(n=46)$, pulmonary disease $(n=43)$, hepatic disease $(n=9)$, renal disease $(n=6)$, neurologic disease $(n=6)$, autoimmune disease $(n=4)$, and HIV / AIDS $(n=1)$.

Chronic disease patients had a median age of 69 years (interquartile range or IQR $=18$ ), with their ages being between 28 and 97 years old. The male to female ratio was 1.22 and there were no statistically significant age differences between men and women. 


\subsection{Phase 2-Palliative Patient's Characteristics}

A sample of 39 patients, eligible from those with chronic disease, fulfilled the PIG criteria. One patient did not consent to participate, resulting in a response rate of $97 \%$. Eight patients were excluded by MMSE. A total of 30 patients were enrolled in the study (Figure 1).

The researcher had negative answers to the PIG surprise question "Would you be surprised if this patient were to die in the next few months, weeks, days?" in five patients, namely: a 34-year-old male with AIDS and plasmablastic non-Hodgkin lymphoma stage IIIB; a 43-year-old female with metastatic colon adenocarcinoma of Dukes C stage; a 77-year-old male with Parkinson's disease, hyperthyroidism, congestive heart disease stage III NYHA, chronic kidney disease stage III and atrial fibrillation; a 91-year-old female with congestive heart disease stage IV NYHA, previous stroke and previous myocardial infarction; and a 92-year-old male with congestive heart disease stage III NYHA, COPD Gold III/stage C and peripheral artery disease.

The researcher identified PIG general indicators of decline in 25 patients, namely: significant co-morbidity $(n=21)$; advanced disease $(n=16)$; general physical decline $(n=8)$; repeated or unplanned crisis admissions $(n=4)$; decreasing reversibility or decreasing response to treatments $(n=3)$; decreasing activity $(n=3)$; increasing need for support $(n=2)$; and progressive weight loss above $10 \%(n=2)$. Nineteen of these 25 patients $(76 \%)$ had more than one general indicator of decline.

Palliative patients included in the study $(n=30)$ had a median age of $77(\mathrm{IQR}=16)$, with their ages being between 34 and 91 years. The male to female ratio was 1.5 and there were no statistically significant age differences between men and women. Most palliative patients were married or living together $(67 \%)$, while the remainder were widowed $(23 \%)$ or single $(10 \%)$. Most had a low-medium socioeconomic status ( $87 \%$ ), a low educational level ( $94 \%$ had four or fewer years of education), and were retired $(90 \%)$. These socioeconomic-educational results reflect an aged sample from a village in Portugal, as it was about half a century ago that people had no proper access to education.

\subsection{Prevalence of Depression and Spiritual Distress}

The prevalence of depression was $23 \%(n=7)$ in this sample. The semi-structured clinical interview identified seven patients with depression. There were scores of $\geq 11$ in the depression subscale in eight patients, meaning probable depression. One of these patients, a woman aged 91, had recently broken her left arm. In this case, the researcher and family physician who previously knew her clinically classified her sadness as an adjustment reaction instead of depression. The agreement between a diagnosis of clinical depression and results of the depression subscale was $87.5 \%$. The prevalence of spiritual distress was $23 \%(n=7)$ in this sample. Depression and spiritual distress criteria co-occurred in four patients $(13 \%)$.

\subsection{Spiritual Distress Palliative Patient's Defining Characteristics}

In the present study, all palliative patients with spiritual distress diagnosis had more than one defining characteristic of spiritual distress (Table 1).

Anger (towards God/divinity or in general), grief, and regret, as well as the need for forgiveness, were the most important defining characteristics in this sample. Additionally, the researcher observed major past traumatic life events in four patients $(57 \%)$ with spiritual distress, such as a false allegation of paternity with major implications, a loss of a young spouse from gunfire homicide, a loss of a young husband, and the loss of a son from suicide. These patients were the 57-year-old male, 68-year-old male, 74-year-old female, and 75-year-old male. Patients with major past traumatic life events presented more defining characteristics of spiritual distress, particularly grief, and three of them (75\%) had a diagnosis of alcoholic use disorder.

\subsection{Depression Palliative Patient's Characteristics}

There were seven palliative patients with a depressive disorder, namely: major depressive disorder $(n=2)$, depressive disorder secondary to Parkinson's disease $(n=2)$, depressive disorder secondary 
to stroke $(n=1)$, persistent depressive disorder/dysthymia $(n=1)$, and adjustment disorder with depressed mood $(n=1)$. Alcoholism was observed in one palliative patient with a depressive disorder, who additionally had a comorbidity of spiritual distress.

\subsection{Statistical Analysis}

A significantly positive association between depression and a lack of meaning in life was found, although the association between depression and expression of suffering was not statistically significant (1A) (Table 2).

Table 2. Depression related to the main defining characteristics of spiritual distress.

\begin{tabular}{ccc}
\hline Depression $(\boldsymbol{n}=\mathbf{7})$ & $\boldsymbol{n}(\%)$ & $p$ Value \\
\hline Expresses suffering $(n=16)$ & $6(37.5)$ & 0.050 \\
Expresses lack of meaning in life $(n=8)$ & $5(62.5)$ & 0.002 \\
\hline
\end{tabular}

Palliative patients with depression had significantly lower FACIT-Sp scores than those who did not have depression (2A) (Table 3). However, the lowest FACIT-Sp scores were associated with the use of sedative or anxiolytic medication (4A), but not with the use of antidepressants (3A) (Table 3).

Table 3. FACIT-Sp scale scores related to depression diagnosis and the use of psychotropic medication.

\begin{tabular}{|c|c|c|c|}
\hline FACIT-Sp Scores $(n=30)$ & & Mean (SD) & $p$ Value \\
\hline Depression & $\begin{array}{c}\text { Yes }(n=7) \\
\text { No }(n=23)\end{array}$ & $\begin{array}{l}28.3(3.2) \\
34.8(6.9)\end{array}$ & 0.023 \\
\hline Antidepressants & $\begin{array}{c}\text { Yes }(n=5) \\
\text { No }(n=25)\end{array}$ & $\begin{array}{l}29.4(5.3) \\
34.0(6.8)\end{array}$ & 0.161 \\
\hline Sedatives/Anxiolytics & $\begin{array}{c}\text { Yes }(n=6) \\
\text { No }(n=24)\end{array}$ & $\begin{array}{l}27.5(4.8) \\
34.7(6.5)\end{array}$ & 0.016 \\
\hline
\end{tabular}

Notes: FACIT-Sp = Functional Assessment of Chronic Illness Therapy-Spiritual Well-Being Scale.

Accordingly, a significant association between spiritual distress and the use of sedative or anxiolytic medication was found, although spiritual distress was not significantly correlated with the use of antidepressants (6A) (Table 4).

Table 4. Psychotropic medication use related to spiritual distress diagnosis.

\begin{tabular}{ccc}
\hline Spiritual Distress $(\boldsymbol{n}=\mathbf{7})$ & $\boldsymbol{n} \mathbf{( \% )}$ & $\boldsymbol{p}$ Value \\
\hline Antidepressants $(n=5)$ & $2(40.0)$ & 0.334 \\
Sedatives / Anxiolytics $(n=6)$ & $4(66.7)$ & 0.005 \\
\hline
\end{tabular}

A significantly negative correlation was found for FACIT-Sp scores with HADS-D and HADS-T scores, although this was not found for HADS-A scores (7A) (Table 5).

Table 5. Correlations between FACIT-Sp scores and HADS scores.

\begin{tabular}{ccc}
\hline FACIT-Sp & Spearman's Rho & $p$ Value \\
\hline HADS-D & -0.64 & $<0.001$ \\
HADS-A & -0.11 & 0.571 \\
HADS-T & -0.56 & 0.001 \\
\hline Note: HADS = Hospital Anxiety and Depression Scale.
\end{tabular}

Moreover, spiritual distress was found to not be associated with HADS scores (6B) (Table 6). 
Table 6. HADS scores related to spiritual distress diagnosis.

\begin{tabular}{ccccccc}
\hline Spiritual Distress & \multicolumn{2}{c}{ HADS-D } & \multicolumn{2}{c}{ HADS-A } & \multicolumn{2}{c}{ HADS-T } \\
\hline & $\mathrm{X}(\min -\max )$ & $p$ value & $\mathrm{X}($ min-max $)$ & $p$ value & $\mathrm{X}(\min -\max )$ & $p$ value \\
\hline Yes $(n=7)$ & $13(3-14)$ & \multirow{2}{*}{0.190} & $\begin{array}{l}6(3-11) \\
5(2-13)\end{array}$ & \multirow{2}{*}{0.774} & $17(9-25)$ & 0.226 \\
No $(n=23)$ & $7(2-14)$ & & & $12(7-27)$ & \\
\hline
\end{tabular}

A significant association was found between alcoholism and spiritual distress diagnosis (6C), although this association was not found with depression (5A) (Table 7). Alcoholism had been codified by ICPC-2 with a code of "P15-Chronic alcohol abuse". These were patients with alcoholic liver disease.

Table 7. Alcoholic liver disease related to depression and spiritual distress.

\begin{tabular}{ccc}
\hline Alcohol $(\boldsymbol{n}=\mathbf{4})$ & $\boldsymbol{n}(\mathbf{\%})$ & $\boldsymbol{p}$ Value \\
\hline Depression $(n=7)$ & $1(14.3)$ & 0.933 \\
Spiritual distress $(n=7)$ & $4(57.1)$ & $<0.001$ \\
\hline
\end{tabular}

\section{Discussion}

This study focused on applying the diagnosis of spiritual distress and depression to the clinical setting, based on their definitions and using selected related scales. We hypothesized that there would be palliative patients with one clinical diagnosis or neither. Our main objective was to describe the clinical and statistical findings of palliative patients with depression and spiritual distress. Thus, we would identify criteria to make a differential diagnosis. Although the study showed promising results, it also has underlying obstacles and limitations that need to be addressed.

The prevalence of depression in the sample $(23 \%)$ is similar to that described in previous research. A systematic review conducted in 2002 summarized the prevalence of depression in advanced diseases according to HADS definition (score on the depression subscale of $>10$ ) as being $29 \%$ (IQR $=19.50-34.25 \%)$. In comparison, according to psychiatric interviews, values fluctuated between $5 \%$ and $26 \%$ (a median of $15 \%$ ) (Hotopf et al. 2002). A more recent meta-analysis, from 2011, found a prevalence of depression defined by the DSM or International Classification of Diseases (ICD) criteria of $16.5 \%$ (95\% confidence interval of 13.1-20.3) in palliative care settings and of $16.3 \%$ (13.4-19.5\%) in oncologic and hematologic settings (Mitchell et al. 2011). Previous research describes a prevalence of spiritual distress varying between $28 \%$ and $44 \%$ in oncology and palliative patients (Delgado-Guay et al. 2011; Hui et al. 2011; Blanchard et al. 2012). In this sample, the prevalence of spiritual distress was $23 \%$. To our knowledge, this is the first study to describe the prevalence of spiritual distress in palliative patients in primary care.

A significant proportion of palliative patients in the sample had a mixed diagnosis of depression and spiritual distress (13\%). Previous research showed that elderly patients admitted to geriatric rehabilitation with significant depressive symptoms might be especially vulnerable to concomitant spiritual distress. In that sample, the proportion of elderly patients with mixed depressive symptoms and spiritual distress was 15.1\%, which is similar to our results (Bornet et al. 2015).

Depression was also found to be positively and significantly related to a lack of meaning in life. Swinton states that "depression is a profound spiritual illness that digs into the heart of a person's spirit and forces them to face experiences of meaninglessness and hopelessness" (Swinton 2001, p. 167). It seems that previous qualitative and quantitative research suggests meaning in life is a core aspect of the human person (Frankl 1992) and a lack of this dimension might be related to depression (Swinton 2001; Guerrero-Torrelles et al. 2017), addiction (White et al. 2006; Krentzman et al. 2015) and spiritual distress (Caldeira et al. 2015; Villagomeza 2005). However, the present study does not explain the nature and direction of the causal relationship between depression and a lack of meaning in life. A recent systematic review about meaning interventions among patients with advanced 
diseases states a core component of all the interventions was "the interpersonal encounter between patient and therapist, in which sources of meaning were explored and a sense of connectedness was re-established" (Guerrero-Torrelles et al. 2017, p. 1). Logotherapeutic approaches led to the same results (Robatmili et al. 2015). In European patients with advanced cancer, interpersonal relationships were reported as the area that provides more meaning in life to these patients (Tomás-Sábado et al. 2015). Among patients with advanced diseases, having a sense of meaning in life is a buffer against depression and the wish to hasten death (Guerrero-Torrelles et al. 2017). In the general population, interventions increasing gratitude and meaning in life facilitate the remission of depression (Disabato et al. 2016).

In accordance with previous literature, the present study found depression to be related to a lack of spiritual well-being. On the whole, depression is related to a lack of spiritual well-being as it relates to a lack of meaning in life, which is a spiritual dimension of the human being (Swinton 2001).

Conversely, in the present study, a lack of spiritual well-being was associated with the use of sedative or anxiolytic medication but not with the use of antidepressants. Although both depression and spiritual distress are associated with lower scores in the FACIT-Sp scale, the FACIT-Sp is a more accurate scale to measure the spiritual dimension compared with the emotional dimension of the human being (Peterman et al. 2002). Therefore, this finding is probably a result of the observed association between spiritual distress and the use of sedative or anxiolytic medication.

A diagnosis of spiritual distress was obtained through three component criteria, which included the patient and the researcher report in addition to a FACIT-Sp score below 36. Recent research considered that the patient's self-report of having spiritual distress and a lower result in a spiritual well-being scale, namely the Spiritual Well-Being Questionnaire, is an accurate resource for measuring spiritual distress (Caldeira et al. 2017). Therefore, depression and spiritual distress correspond to distinct dimensions despite being related and might require different therapeutic interventions (Bornet et al. 2015).

Other than a lack of meaning in life and expression of suffering, the most frequent defining characteristics for spiritual distress observed in the present sample were anger (towards God/divinity or in general), grief, and regret, as well as the need for forgiveness. Sedative or anxiolytic medication might be a means of muting the patient's spiritual suffering. "A man's concern, even his despair, over the worthwhileness of life is a spiritual distress but by no means a mental disease. It may well be that interpreting the first in terms of the latter motivates a doctor to bury his patient's existential despair under a heap of tranquilizing drugs. It is his task, rather, to pilot the patient through his existential crises of growth and development" (Frankl 1985, p. 125). However, the use of anxiolytic/sedative medication can also be a supportive and therapeutic measure until the patient overcomes his spiritual suffering.

The researcher observed the occurrence of major past traumatic life events in four patients $(57 \%)$ with spiritual distress, who presented more defining characteristics of spiritual distress compared with the other patients with spiritual distress. Other defining characteristics of spiritual distress observed in this subset group of patients were grief, anger (towards God/divinity or in general), need for forgiveness and alienation. Additional studies on the subject might aid in the acknowledgement of spiritual distress.

As previously discussed, through the application of FACIT-Sp scale and DSM- 5 criteria, we found a lack of spiritual well-being to be related to depression. Consequently, FACIT-Sp was found to be negatively related to HADS-D and HADS-T. The interesting finding was the lack of association between FACIT-Sp scores and HADS-A. Although depression and anxiety commonly co-occur, share several physical (e.g., insomnia, weight loss) and emotional features (e.g., stress and unrest) as well as having common underlying physiologic processes (Kreitler 2017), they are distinct pathologies exhaustively described in the DSM-5 classification. A recent study aimed at contributing to the clarification of the distinctiveness of anxiety and depression in terms of their cognitive characteristics, as reflected in their tendencies to assign meaning, concluded that anxiety and depression were different constructs, as the "anxiety profile indicated more focusing on one's internal world whereas the depression profile indicated focusing both on the personal and the interpersonally-shared reality" (Kreitler 2017, p. 1). 
In the present study, HADS was not significantly associated with a diagnosis of spiritual distress. Apart from the similarities between depression and spiritual distress, they seem to represent distinct dimensions, as highlighted by Frankl and Bornet (Frankl 1985; Bornet et al. 2015).

In the present study, a significantly positive association was found between spiritual distress and alcoholism, which implicitly involved an expression of suffering and a lack of meaning in life. As emphasized by Gerwood, clients with addiction try to fill their existential vacuum with alcohol and other drugs (Gerwood 1998; Kleftaras and Katsogianni 2012), which makes them excellent candidates for understanding the concept of the existential vacuum as described by Frankl (a dimension of the meaning of life construct that encapsulates the failure of a person to experience meaning in life) (Frankl 1968). Alcoholics have a lower sense of meaning in life than non-alcoholics, with their sense of life purpose increasing during treatment programs for alcohol addiction (White et al. 2006; Kleftaras and Katsogianni 2012). Patients with alcoholism find meaning in survival, self-reclamation, service to others, and connections to the community (White et al. 2006).

It seems that qualitative and quantitative research suggests a meaning in life is a core aspect of the human person and a lack of this dimension might be related to depression, addiction, and spiritual distress. Conversely, depression has been associated with alcohol use disorder, especially in older people (Conner et al. 2009). Furthermore, previous research suggests that elderly patients with significant depressive symptoms might be more vulnerable to spiritual distress (Bornet et al. 2015). A recent study of alcoholics showed higher levels of feelings of emptiness in those with higher levels of depressive symptomatology (Kleftaras and Katsogianni 2012). Although depression and spiritual distress can co-occur, there is a gap in the research about the prevalence of spiritual distress in alcoholic use disorder.

The present study was designed toward differentiating depression from spiritual distress, which might have made possible the observed relation between alcoholism and spiritual distress but not with depression. Considering the theoretical and practical relations between spiritual distress and a lack of meaning in life (Caldeira et al. 2015; Villagomeza 2005) as well as between lack of meaning in life and alcoholism (White et al. 2006; Krentzman et al. 2015), the findings of the present study have a theoretical background. The observed relationship between spiritual distress and alcoholism might create an opportunity for practical research in the field.

This study underlines the importance of assessing spiritual distress in palliative patients, particularly in primary care. Primary health care professionals are at a privileged position in the delivery of care. Proximity to the patients and their family in addition to continuity of care are common issues in palliative and primary care. Recognizing spiritual distress as well as introducing guided mental and holistic care and referrals to the proper spiritual, social, or other health care facilities, including palliative care, can promote better quality of life for palliative patients at an earlier phase.

\section{Conclusions}

This study aimed to identify the prevalence in addition to the clinical indicators of depression and spiritual distress in palliative patients in primary care. Depression and spiritual distress seem to both be linked to the spiritual dimension of the human being, but seem to differ in the dimensions of suffering and the pharmacological treatment.

This study has three important findings: (1) apart from being associated with a lack of spiritual well-being, depression seems to be related to a lack of meaning in life, which is a core aspect of spiritual distress. Therefore, if this is true, depression is also a spiritual experience as having a meaning in life is a transcendent, personal, and unique experience; (2) depression seems to differ from spiritual distress, at least in two clinical indicators: there seems to be an association between relevant traumatic life events and spiritual distress. Furthermore, spiritual distress seems to be associated with alcoholism, although this was not seen for depression; (3) medical treatment for spiritual distress seems more prone to the use of anxiolytic medication instead of antidepressants. 
The study is limited by its cross-sectional design and the small sample size will greatly reduce the validity and generalizability of the study findings and is a significant weakness of this investigation. The participants' educational background might have yielded some bias during filling in the questionnaires, although some assistance in readings had been provided by personal assistants. Conclusions should be understood in this sample and context.

The authors believe the paper suggests two possible clinical markers of spiritual distress: alcoholism and past traumatic life events. The association between the use of anxiolytic medication and spiritual distress in primary care palliative patients will need to be further studied and, if so confirmed, there needs to be an examination of the proper class or drug that works best for this clinical entity. Palliative patients' depression and spiritual distress need to be precisely identified for correct decision-making in addition to pinpointing the most effective treatment and holistic care. Further research, including broader samples and different cultural backgrounds, is needed.

Acknowledgments: The authors are grateful to all participants, and to the health care unit administrative assistants, who cooperated in the study.

Author Contributions: Teresa Velosa, Sílvia Caldeira, and Manuel Luís Capelas conceived and designed the study; Teresa Velosa collected the data; Teresa Velosa and Manuel Luís Capelas treated the data; Teresa Velosa, Sílvia Caldeira, and Manuel Luís Capelas wrote the paper.

Conflicts of Interest: The authors declare no conflict of interest.

\section{Abbreviations}

The following abbreviations are used in this manuscript:

$\begin{array}{ll}\text { AIDS } & \text { Acquired Immune Deficiency Syndrome } \\ \text { COPD } & \text { Chronic Obstructive Pulmonary Disease } \\ \text { DSM } & \text { Diagnostic and Statistical Manual of Mental Disorders } \\ \text { FACIT-Sp } & \text { Functional Assessment of Chronic Illness Therapy_-Spiritual Well-Being Scale } \\ \text { GDS } & \text { Geriatric Depression Scale } \\ \text { GP } & \text { General Practitioner } \\ \text { HADS } & \text { Hospital Anxiety and Depression Scale } \\ \text { ICD } & \text { International Classification of Diseases } \\ \text { ICPC-2 } & \text { International Classification for Primary Care-2 } \\ \text { IQR } & \text { Interquartile Range } \\ \text { MMSE } & \text { Mini Mental State Examination } \\ \text { NYHA } & \text { New York Heart Association } \\ \text { PIG } & \text { Prognostic Indicator Guidance } \\ \text { SDAT } & \text { Spiritual Distress Assessment Tool }\end{array}$

\section{References}

APA. 2013. Diagnostic and Statistical Manual of Mental Disorders (DSM- $\left.5^{\circledR}\right)$, 5th ed. Arlington: American Psychiatric Pub., pp. 1-970, ISBN-13: 978-0890425558.

Bekelman, David B., Sydney M. Dy, Diane M. Becker, Ilan S. Wittstein, Danetta E. Hendricks, Tracy E. Yamashita, and Sheldon H. Gottlieb. 2007. Spiritual Well-Being and Depression in Patients with Heart Failure. Journal of General Internal Medicine 22: 470-77. [CrossRef] [PubMed]

Blanchard, Judith H., Douglas A. Dunlap, and George Fitchett. 2012. Screening for spiritual distress in the oncology inpatient: A quality improvement pilot project between nurses and chaplains. Journal of Nursing Management 20: 1076-84. [CrossRef] [PubMed]

Bornet, Marc-Antoine, Etienne Rochat, Anne-Véronique Dürst, Sarah Fustinoni, Christophe Büla, Armin von Gunten, and Stéfanie Monod. 2015. Instruments to Assess Depressive Symptoms and Spiritual Distress Investigate Different Dimensions. Clinical Gerontologist 39: 104-16. [CrossRef]

Caldeira, Sílvia, Emília Campos Carvalho, and Margarida Vieira. 2013. Spiritual distress-proposing a new definition and defining characteristics. International Journal of Nursing Knowledge 24: 77-84. [CrossRef] [PubMed] 
Caldeira, Sílvia, Emilia Campos de Carvalho, and Margarida Vieira. 2014. Between spiritual wellbeing and spiritual distress: Possible related factors in elderly patients with cancer. Revista Latino-Americana De Enfermagem 22: 28-34. [CrossRef] [PubMed]

Caldeira, Sílvia, Fiona Timmins, Emília Campos Carvalho, and Margarida Vieira. 2015. Clinical Validation of the Nursing Diagnosis Spiritual Distress in Cancer Patients Undergoing Chemotherapy. International Journal of Nursing Knowledge 28: 44-52. [CrossRef] [PubMed]

Caldeira, Sílvia, Fiona Timmins, Emília Campos de Carvalho, and Margarida Vieira. 2017. Spiritual Well-Being and Spiritual Distress in Cancer Patients Undergoing Chemotherapy: Utilizing the SWBQ as Component of Holistic Nursing Diagnosis. Journal of Religion and Health 56: 1489-502. [CrossRef] [PubMed]

Conner, Kenneth R., Martin Pinquart, and Stephanie A. Gamble. 2009. Meta-analysis of depression and substance use among individuals with alcohol use disorders. Journal of Substance Abuse Treatment 37: 127-37. [CrossRef] [PubMed]

Cukor, Daniel, Jeremy Coplan, Clinton Brown, Steven Friedman, Howard Newville, Michal Safier, Lisa A. Spielman, Rolf A. Peterson, and Paul L. Kimmel. 2008. Anxiety Disorders in Adults Treated by Hemodialysis: A Single-Center Study. American Journal of Kidney Diseases 52: 128-36. [CrossRef] [PubMed]

Cukor, Daniel, Nisha Ver Halen, Deborah Rosenthal Asher, Jeremy D. Coplan, Jeremy Weedon, Katarzyna E. Wyka, Subodh J. Saggi, and Paul L. Kimmel. 2014. Psychosocial Intervention Improves Depression, Quality of Life, and Fluid Adherence in Hemodialysis. Journal of the American Society of Nephrology 25: 196-206. [CrossRef] [PubMed]

De Cássia Lopes Chaves, Erika, Emilia Campos de Carvalho, Fabio de Souza Terra, and Luiz de Souza. 2010. Clinical validation of impaired spirituality in patients with chronic renal disease. Revista Latino-Americana de Enfermagem 18: 309-16. [CrossRef] [PubMed]

Delgado-Guay, Marvin O., David Hui, Henrique A. Parsons, Kathy Govan, Maxine De la Cruz, Steven Thorney, and Eduardo Bruera. 2011. Spirituality, religiosity, and spiritual pain in advanced cancer patients. Journal of Pain and Symptom Management 41: 986-94. [CrossRef] [PubMed]

Disabato, David J., Todd B. Kashdan, Jerome L. Short, and Aaron Jarden. 2016. What Predicts Positive Life Events that Influence the Course of Depression? A Longitudinal Examination of Gratitude and Meaning in Life. Cognitive Therapy and Research 41: 444-58. [CrossRef]

Durà-Vilà, Glòria, Simon Dein, Roland Littlewood, and Gerard Leavey. 2010. The Dark Night of the Soul: Causes and Resolution of Emotional Distress Among Contemplative Nuns. Transcultural Psychiatry 47: 548-70. [CrossRef] [PubMed]

Frankl, Viktor E. 1968. O Homem Incondicionado: Lições Metaclínicas. Translated by G. Oliveira. Coimbra: Amado, pp. 1-202.

Frankl, Viktor E. 1985. Man's Search for Meaning. New York: Washington Square Press, pp. 1-224. ISBN 0-671-66736-X.

Frankl, Viktor E. 1992. Teoría y Terapia de Las Neuroses. Iniciación a La Logoterapia y a la Análisis Existencial. Barcelona: Herder, pp. 1-292. ISBN-10: 84-254-1768-6.

Gerwood, Joseph B. 1998. The existential vacuum in treating substance-related disorders. Psychological reports 83: 1394. [CrossRef] [PubMed]

Gielen, Joris, Sushma Bhatnagar, and Santosh K. Chaturvedi. 2017. Prevalence and Nature of Spiritual Distress among Palliative Care Patients in India. Journal of Religion and Health 56: 530-44. [CrossRef] [PubMed]

Guerrero-Torrelles, Mariona, Cristina Monforte-Royo, Andrea Rodríguez-Prat, Josep Porta-Sales, and Albert Balaguer. 2017. Understanding meaning in life interventions in patients with advanced disease: A systematic review and realist synthesis. Palliative Medicine. Available online: http://journals.sagepub. com/doi/abs/10.1177/0269216316685235 (accessed on 2 May 2017).

Haworth, J. E., E. Moniz-Cook, A. L. Clark, M. Wang, R. Waddington, and J. G. F. Cleland. 2005. Prevalence and predictors of anxiety and depression in a sample of chronic heart failure patients with left ventricular systolic dysfunction. European Journal of Heart Failure 7: 803-8. [CrossRef] [PubMed]

Hirschfeld, Robert MA. 2001. The Comorbidity of Major Depression and Anxiety Disorders: Recognition and Management in Primary Care. Primary Care Companion to the Journal of Clinical Psychiatry 3: 244-54. [CrossRef] [PubMed] 
Hotopf, M., J. Chidgey, J. Addington-Hall, and K. Lan Ly. 2002. Depression in advanced disease: A systematic review Part 1. Prevalence and case finding. Palliative Medicine 16: 81-97. [CrossRef] [PubMed]

Hui, David, Maxine de la Cruz, Steve Thorney, Henrique A. Parsons, Marvin Delgado-Guay, and Eduardo Bruera. 2011. The Frequency and Correlates of Spiritual Distress Among Patients With Advanced Cancer Admitted to an Acute Palliative Care Unit. American Journal of Hospice \& Palliative Medicine 28: 264-70. [CrossRef]

Kleftaras, George, and Irene Katsogianni. 2012. Spirituality, Meaning in Life, and Depressive Symptomatology in Individuals with Alcohol Dependence. Journal of Spirituality in Mental Health 14: 268-88. [CrossRef]

Kreitler, Shulamith. 2017. The meaning profiles of anxiety and depression: Similarities and differences in two age groups. Cognition E Emotion. Available online: http:/ / dx.doi.org/10.1080/02699931.2017.1311248 (accessed on 2 June 2017).

Krentzman, Amy R., James A. Cranford, and Elizabeth A. R. Robinson. 2015. Long-Term Increases in Purpose in Life are Associated with Remission from Alcohol Dependence. Alcoholism Treatment Quarterly 33: $252-69$. [CrossRef]

Kunik, Mark E., Kent Roundy, Connie Veazey, Julianne Souchek, Peter Richardson, Nelda P. Wray, and Melinda A. Stanley. 2005. Surprisingly High Prevalence of Anxiety and Depression in Chronic Breathing Disorders. Chest 127: 1205-11. [CrossRef]

Loosen, Peter T., John L. Beyer, Sam R. Sells, Harry E. Gwirtsman, Richard C. Shelton, Pryor Baird, and James L. Nash. 2000. Mood Disorders. In Current Diagnostic \& Treatment in Psychiatry. Edited by Michael H. Ebert, Peter T. Loosen and Barry Nurcombe. Lisbon: Lange Medical Books/McGraw-Hill, pp. 290-327. ISBN 0-8385-1462-6.

McClain, Colleen S., Barry Rosenfeld, and William Breitbart. 2003. Effect of spiritual well-being on end-of-life despair in terminally-ill cancer patients. Lancet 361: 1603-7. [CrossRef]

Mistry, Bina, Daryl Bainbridge, Deanna Bryant, Sue Tan Toyofuku, and Hsien Seow. 2015. What matters most for end-of-life care? Perspectives from community-based palliative care providers and administrators. BMJ Open 5: e007492. [CrossRef] [PubMed]

Mitchell, Alex J., Melissa Chan, Henna Bhatti, Marie Halton, Luigi Grassi, Christoffer Johansen, and Nicholas Meader. 2011. Prevalence of depression, anxiety, and adjustment disorder in oncological, haematological, and palliative-care settings: A meta-analysis of 94 interview-based studies. The Lancet Oncology 12: 160-74. [CrossRef]

Moreira-Almeida, Alexander, Avdesh Sharma, Bernard Janse van Rensburg, Peter J. Verhagen, and Christopher C.H. Cook. 2016. WPA Position Statement on Spirituality and Religion in Psychiatry. World Psychiatry 15: 87-88. [CrossRef] [PubMed]

Morgado, Joana, Cláudia Susana Rocha, Carolina Maruta, Manuela Guerreiro, and Isabel Pavão Martins. 2009. New Normative Values of Mini-Mental State Examination. Sinapse 9: 10-18.

Moussavi, Saba, Somnath Chatterji, Emese Verdes, Ajay Tandon, Vikram Patel, and Bedirhan Ustun. 2007. Depression, chronic diseases, and decrements in health: Results from the World Health Surveys. Lancet 370: 851-58. [CrossRef]

Murray, Scott A., Marilyn Kendall, Kirsty Boyd, and Aziz Sheikh. 2005. Illness trajectories and palliative care. BMJ 330: 1007-11. [CrossRef] [PubMed]

Naghi, Jesse J., Kiran J. Philip, Anita Phan, Laurent Cleenewerck, and Ernst R. Schwarz. 2012. The effects of spirituality and religion on outcomes in patients with chronic heart failure. Journal of Religion and Health 51: 1124-36. [CrossRef] [PubMed]

Pais-Ribeiro, José, Isabel Silva, Teresa Ferreira, A. Martins, Rute Meneses, and M. Baltar. 2007. Validation study of a Portuguese version of the Hospital Anxiety and Depression Scale. Psychology, Health E Medicine 12: 225-35. [CrossRef]

Pereira, Filomena, and Célia Santos. 2011. Functional Assessment of Chronic Illness Therapy -Spiritual Well -Being (FACIT -Sp): Validation study in end of life cancer patients. Cadernos de Saúde 4: 37-45.

Peterman, Amy H., George Fitchett, Marianne J. Brady, Lesbia Hernandez, and David Cella. 2002. Measuring spiritual well-being in people with cancer: The functional assessment of chronic illness therapy-Spiritual well-being scale (FACIT-Sp). Annals of Behavioral Medicine 24: 49-58. [CrossRef] [PubMed]

Puchalski, Christina, Betty Ferrell, Rose Virani, Shirley Otis-Green, Pamela Baird, Janet Bull, and Harvey Chochinov. 2009. Improving the quality of spiritual care as a dimension of palliative care: The report of the Consensus Conference. Journal of Palliative Medicine 12: 885-904. [CrossRef] [PubMed] 
Risk, James L. 2013. Building a new life: A chaplain's theory based case study of chronic illness. Journal of Health Care Chaplaincy 19: 81-98. [CrossRef] [PubMed]

Robatmili, Somaye, Faramarz Sohrabi, Mohammad Ali Shahrak, Siavash Talepasand, Mostafa Nokani, and Mohaddese Hasani. 2015. The Effect of Group Logotherapy on Meaning in Life and Depression Levels of Iranian Students. International Journal for the Advancement of Counselling 37: 54-62. [CrossRef] [PubMed]

Saisunantararom, Waraporn, Areewan Cheawchanwattana, Talerngsak Kanjanabuch, Maliwan Buranapatana, and Kornkaew Chanthapasa. 2015. Associations among Spirituality, Health-Related Quality of Life, and Depression in Pre-Dialysis Chronic Kidney Disease Patients: An Exploratory Analysis in Thai Buddhist Patients. Religions 6: 1249-62. [CrossRef]

Sankar, Anjali, Tianhao Zhang, Bilwaj Gaonkar, Jimit Doshi, Guray Erus, Sergi G. Costafreda, Lauren Marangell, Christos Davatzikos, and Cynthia HY Fu. 2016. Diagnostic potential of structural neuroimaging for depression from a multi-ethnic community sample. British Journal of Psychiatry Open 2: 247-54. [CrossRef] [PubMed]

Selman, Lucy, Teresa Young, Mieke Vermandere, Ian Stirling, and Carlo Leget. 2014. Research priorities in spiritual care: An international survey of palliative care researchers and clinicians. Journal of Pain and Symptom Management 48: 518-31. [CrossRef] [PubMed]

Shelton, Richard C. 2000. Anxiety Disorders. In Current Diagnostic \& Treatment in Psychiatry. Edited by Michael H. Ebert, Peter T. Loosen and Barry Nurcombe. Lisbon: Lange Medical Books/McGraw-Hill, pp. 218-40. ISBN 0-8385-1462-6.

Stein, Edith. 1994. Ser Finito y Ser Eterno. Ensayo de Una Ascención al Sentido del Ser. Fondo de Cultura Económica: Mexico, p. 552. ISBN 968-16-4219-8.

Strada, E. Alessandra, Peter Homel, Sharon Tennstedt, J. Andrew Billings, and Russell K. Portenoy. 2013. Spiritual well-being in patients with advanced heart and lung disease. Palliat and Support Care 11: 205-13. [CrossRef] [PubMed]

Swinton, John. 2001. Spirituality and Mental Health Care Rediscovering a 'Forgotten' Dimension, 2nd ed. London: Jessica Kingsler Publishers, pp. 1-221. ISBN 1-85302-804-5.

Keri Thomas, Julie Armstrong Wilson, and GSF Team. 2011. Prognostic Indicator Guidance (PIG). The Gold Standards Framework Centre in End of Life Care CIC. Available online: http:/ / www.goldstandardsframework.org.uk/cd-content/uploads/files/General\%20Files/Prognostic\% 20Indicator\%20Guidance\%20October\%202011.pdf (accessed on 28 February 2015).

Tomás-Sábado, Joaquín, Christian Villavicencio-Chávez, Cristina Monforte-Royo, Mariona Guerrero-Torrelles, Martin Johannes Fegg, and Albert Balaguer. 2015. What Gives Meaning in Life to Patients With Advanced Cancer? A Comparison between Spanish, German, and Swiss Patients. Journal of Pain and Symptom Management 50: 861-6. [CrossRef] [PubMed]

Villagomeza, Liwliwa R. 2005. Spiritual distress in adult cancer patients: Toward conceptual clarity. Holistic Nursing Practice 19: 285-94. [CrossRef] [PubMed]

White, W., A. Laudet, and J. Becker. 2006. Life Meaning and Purpose in Addiction Recovery. The counselor can help clients identify meaning that fits their value system. Addiction Professional 7: 56-59. Available online: https: / / www.addictionpro.com/article/life-meaning-and-purpose-addiction-recovery (accessed on 27 May 2017).

WHO. 2014. Global status report on alcohol and health 2014. Edited by World Health Organization. Geneva. Available online: http:/ /apps.who.int/iris/bitstream/10665/112736/1/9789240692763_eng.pdf (accessed on 27 May 2017).

WHO. 2015. Palliative Care Fact sheet N402. World Health Organization. Available online: http:/ /www.who. int/mediacentre/factsheets/fs402/en/ (accessed on 6 September 2016).

Williams, Sophronia R., Cornelia K. Beck, and Ruth P. Rawlins. 1993. Mental Health-psychiatric Nursing: A Holistic Life-cycle Approach. London: St. Louis, pp. 1-960. ISBN 0-8016-6331-8.

Wilson, Keith G., Harvey Max Chochinov, Merika Graham Skirko, Pierre Allard, Srini Chary, Pierre R. Gagnon, and Karen Macmillan. 2007. Depression and anxiety disorders in palliative cancer care. Journal of Pain and Symptom Management 33: 118-29. [CrossRef] [PubMed] 
Yang, Chun-Tien, Aru Narayanasamy, and Sung-Ling Chang. 2012. Transcultural spirituality: The spiritual journey of hospitalized patients with schizophrenia in Taiwan. Journal of Advanced Nursing 68: 358-67. [CrossRef] [PubMed]

Yohannes, A. M., T. G. Willgoss, R. C. Baldwin, and M. J. Connolly. 2010. Depression and anxiety in chronic heart failure and chronic obstructive pulmonary disease: Prevalence, relevance, clinical implications and management principles. International Journal of Geriatric Psychiatry 25: 1209-21. [CrossRef] [PubMed] 